\title{
A Nonsense Mutation in the Apolipoprotein C-II Padova Gene in a Patient with Apolipoprotein C-II Deficiency
}

\author{
S. S. Fojo, P. Lohse, C. Parrott, G. Baggio, ${ }^{*}$ C. Gabelli, ${ }^{*}$ F. Thomas, J. Hoffman, and H. B. Brewer, Jr. \\ Molecular Disease Branch, National Heart, Lung, and Blood Institute, National Institutes of Health, \\ Bethesda, Maryland 20892; and *University of Padova, Padova, Italy
}

\begin{abstract}
The apo C-II gene from a patient with apo C-II deficiency has been sequenced after amplification by the polymerase chain reaction. A substitution of an adenosine for a guanosine at position 3002 in exon 3 of the patient's gene was identified by sequence analysis. This mutation leads to the introduction of a premature termination codon (TAA) at a position corresponding to amino acid 37 of mature apo $\mathrm{C}$-II and to the formation of a new Rsa I restriction enzyme site not present in the normal apo C-II gene. Amplification of DNA from family members by the polymerase chain reaction and digestion with Rsa I established that the patient is a true homozygote for the mutation. Analysis of the patient's plasma by two-dimensional gel electrophoresis and immunoblotting detected an apo C-II that exhibited abnormal electrophoretic mobility. We propose that the $\mathbf{C}$ to $\mathrm{A}$ substitution in the apo $\mathrm{C}-\mathrm{II}_{\text {Padova }}$ gene is the primary genetic defect that leads to premature termination and the synthesis of a truncated 36 amino acid apo C-II that is unable to activate lipoprotein lipase.
\end{abstract}

\section{Introduction}

Apo C-II is a 79 amino acid protein that plays a central role in triglyceride metabolism as a cofactor for the enzyme lipoprotein lipase (1). In the presence of apo C-II lipoprotein lipase hydrolyzes triglycerides present in chylomicrons and VLDL to monoglycerides, diglycerides, and FFA. The importance of apo C-II as a physiological activator of lipoprotein lipase was established by the identification of patients with a deficiency of apo C-II, a rare disease inherited as an autosomal recessive trait (2-8). Patients with apo C-II deficiency develop type I hyperlipoproteinemia with fasting chylomicronemia and hypertriglyceridemia. Clinical features include eruptive xanthomas, lipemia retinalis, hepatosplenomegaly, and an increased risk of pancreatitis. The diagnosis of apo C-II deficiency is established by finding a virtual absence of apo C-II in plasma associated with reduced postheparin lipoprotein lipase activity that is corrected by the addition of normal apo C-II-containing plasma. In two patients evidence of a circulating inhibitor of lipoprotein lipase activity has been described $(9,10)$.

We have recently described the genetic defect that leads to deficiency of apo C-II in the probands from the Hamburg and

Address correspondence to Dr. Fojo, Molecular Disease Branch, National Heart, Lung, and Blood Institute, National Institutes of Health, Bethesda, MD 20892.

Received for publication 5 June 1989 and in revised form 17 July 1989.

The Journal of Clinical Investigation, Inc.

Volume 84, October 1989, 1215-1219
Nijmegen kindreds $(11,12)$. Sequence analysis of the apo C$\mathrm{II}_{\text {Hamburg }}$ gene revealed a single base substitution that leads to abnormal splicing of the apo $\mathrm{C}-\mathrm{II}_{\text {Hamburg }}$ mRNA. Reduced levels of normal apo C-II could be detected in the plasma of the proband from the Hamburg kindred plasma by two-dimensional gel electrophoresis and immunoblotting. In the apo C- II $_{\text {Nijmegen }}$ DNA, a deletion of a guanosine results in the introduction of a premature termination mutation and the synthesis of a truncated 17 amino acid peptide instead of the 79 residues present in normal apo C-II. However, this peptide was not detected in the patient's plasma by RIA or immunoblot analysis. The defects in apo C-II Toronto $_{\text {(13) and apo C-II }}$ St. Michael (14) have been studied at the protein level. Both of these mutant apo can be easily detected in plasma, are nonfunctional, and have an altered amino acid sequence at the carboxyl-terminal end.

In the present manuscript we investigate the genetic defect in the apo C-II gene of the proband from the Padova kindred. A novel substitution of a cytosine for an adenosine at position 3002 of the third exon of the apo $\mathrm{C}-\mathrm{II}_{\text {Padova }}$ gene has been identified by sequence analysis. This mutation introduces a premature termination codon in the apo $\mathrm{C}-\mathrm{II}_{\text {Padova }}$ gene that leads to the synthesis of a truncated apo C-II peptide. We propose that this base substitution ultimately leads to the deficiency of apo C-II observed in this kindred.

\section{Methods}

Experimental subjects. The two affected individuals from the Padova kindred have been previously described (15).

DNA and RNA preparation. RNA was isolated from frozen liver using the guanidine thiocyanate method (16) and DNA was prepared from white blood cells as previously described (17). Liver tissue was obtained from the patient during open abdominal surgery for cholecystectomy.

Sequence amplification with Taq I DNA polymerase. $1 \mu \mathrm{g}$ of genomic DNA from control and apo C-II-deficient subjects was amplified by the automated polymerase chain reaction (PCR) technique (18) for 30 cycles using Taq I DNA polymerase (Perkin-Elmer Corp., Norwalk, CT) and 50-bp primers containing the restriction enzyme sites for Hind III and Xba I. The amplified region included bases 2616-3133 of the apo C-II gene (19). The PCR reactions were performed with 2-min extensions at $72^{\circ} \mathrm{C}, 30$-s denaturation at $95^{\circ} \mathrm{C}$, and primer annealing at $55^{\circ} \mathrm{C}$. One-tenth of the total amplified DNA was digested with $2 \mathrm{U}$ of Rsa I (Bethesda Research Laboratories, Bethesda, MD) for $2 \mathrm{~h}$. The digested fragments were separated on a $4 \%$ agarose (FC BioProducts, Rockland, ME) Tris acetate EDTA (pH 8.3) minigel at $85 \mathrm{~V}$ for $1 \mathrm{~h}$. DNA was identified by staining with ethidium bromide. Amplified DNA was digested with Hind III and Xba I and subcloned into M13 vector DNA for sequencing. Synthetic oligonucleotides were synthesized by the phosphoramidite method of oligonucleotide synthesis in 


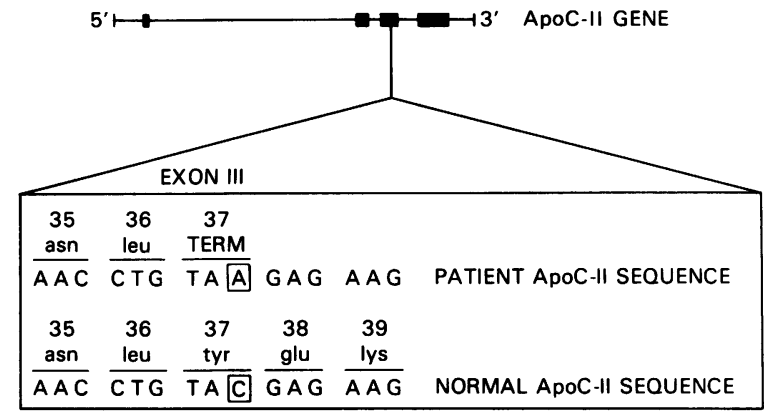

Figure 1. Schematic representation of the apo C-II gene. Exons are illustrated by the solid bars interrupted by lines that represent introns. The patient and normal apo $\mathrm{C}$-II sequences are shown. The $\mathrm{C}$ to A mutation is highlighted by a box.

a DNA synthesizer (model 380B; Applied Biosystems Inc., Foster City, CA).

DNA sequencing. Single-stranded DNA sequencing from M13 vector DNA was performed by the dideoxynucleotide chain termination method of Sanger (20).

Southern and Northern blot hybridization. Southern blot hybridization was performed after digestion of $20 \mu \mathrm{g}$ of normal or patient DNA with the restriction enzyme Rsa I (Bethesda Research Laboratories) as described (17). Gels for Northern blot analysis were prepared with $1 \%$ agarose in the presence of $6 \%$ formaldehyde, electrophoresed at $25 \mathrm{~V}$ for $16 \mathrm{~h}$, and transferred to nitrocellulose filters (Schleicher and Schuell, Inc., Keene, NH) as described previously (21). $8 \mu \mathrm{g}$ of total RNA was analyzed and gels were stained with ethidium bromide to confirm that equivalent quantities of RNA were electrophoresed in each lane.

Peptide synthesis. The truncated 36 amino acid apo C-II Padova $_{\text {pep- }}$ tide was synthesized by the Merrifeld solid phase method using a synthesizer (model 990B; Beckman Instruments, Inc., Palo Alto, CA) and the phenylacetamidomethyl resin as described in detail previously (22).

Electrophoretic analysis of the plasma apo C-II protein. Two-dimensional gel electrophoresis of plasma, consisting of isoelectric focusing followed by SDS gel electrophoresis, was performed as de- scribed (23). The gels were stained by the silver stain method (24). The proteins separated by two-dimensional gel electrophoresis were transferred to nitrocellulose paper at $80 \mathrm{~V}$ for $1 \mathrm{~h}$. Apo C-II was detected by using a monospecific rabbit apo C-II antisera as the first antibody and visualized by indirect immunoperoxidase assay on nitrocellulose paper according to the manufacturer's instructions (Bio-Rad Laboratories, Richmond, CA).

\section{Results}

Sequence analysis of the four exons, all splice junctions, and the $5^{\prime}$ and $3^{\prime}$ untranslated regions of the apo $\mathrm{C}$ - $\mathrm{II}_{\text {Padova }}$ gene revealed a single base substitution at position 3002 (data not shown). Fig. 1 illustrates the genomic organization of the apo $\mathrm{C}$-II gene and the position of the $\mathrm{C}$ to $\mathrm{A}$ mutation in exon 3 identified during the sequence analysis of the apo $\mathrm{C}-\mathrm{II}_{\text {Padova }}$ gene. This substitution leads to the introduction of a premature termination codon (TAA) at a position corresponding to amino acid 37 of the normal apo C-II and, ultimately, to the synthesis of a truncated 36 amino acid apo C-II peptide. Fig. 2 contains autoradiography of sequencing gels of the DNA from normal and apo C-II-deficient subjects in the region of the mutation. The $C$ to A substitution in base 3002 of the patient's apo C-II gene is indicated by the arrow.

Computer analysis (Fristensky-Cornell DNA Sequencing Analysis Program) of the apo $\mathrm{C}$ - $\mathrm{II}_{\text {Padova }}$ gene sequence containing the $\mathrm{C}$ to $\mathrm{A}$ mutation revealed the loss of an Rsa I restriction enzyme site present at position 3000 of the normal apo C-II gene (19). Amplifications of the apo C-II genes from normal and apo C-II-deficient subjects were performed by the PCR as illustrated in Fig. 3. Digestion of amplified normal DNA with Rsa I should result in the formation of two fragments of 385 and $132 \mathrm{bp}$. Digestion of DNA amplified from the patient, however, should lead to the formation of a single fragment of 517 bp (Fig. 3) as the Rsa I restriction enzyme site was destroyed by the mutation.

Fig. 4 illustrates the analysis of DNA isolated from the two apo C-II-deficient individuals and the immediate family members from the Padova kindred after amplification by the
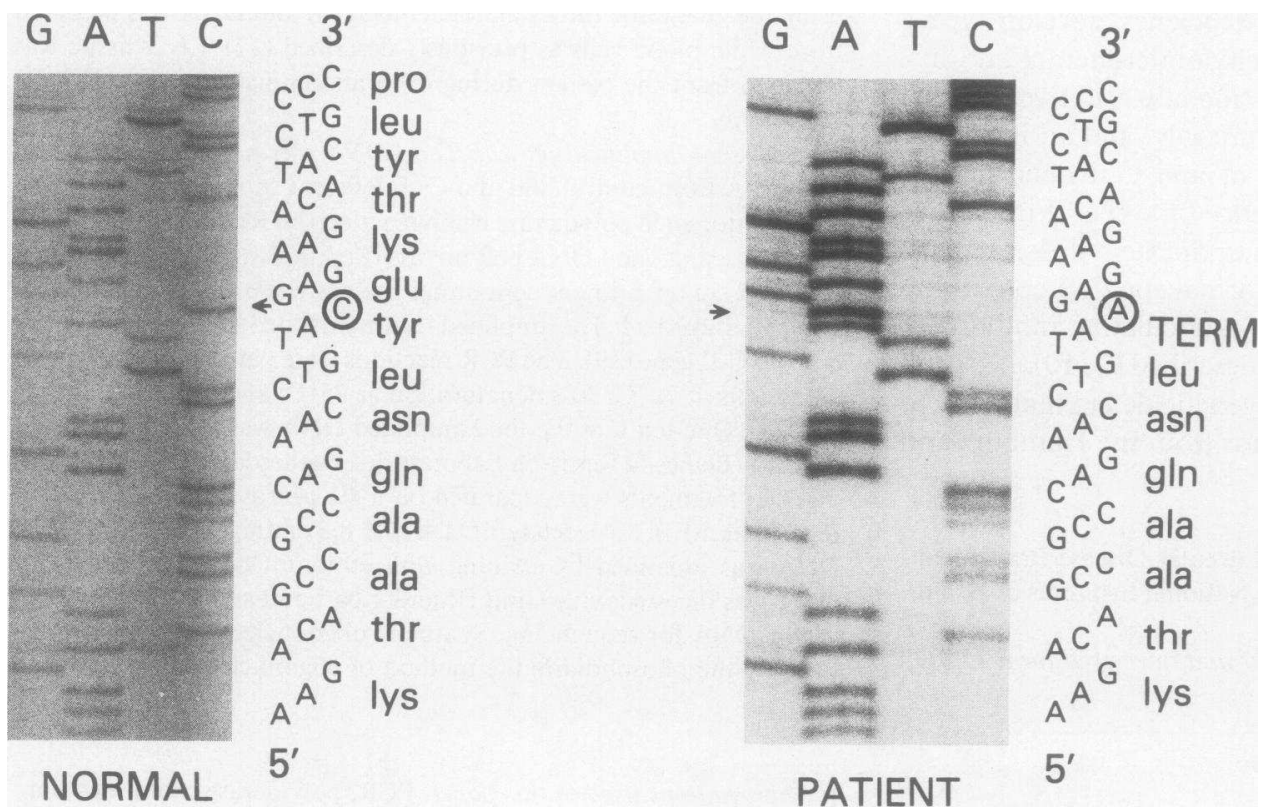

Figure 2. Autoradiography of sequencing gels of DNA from normal and apo C-II-deficient subjects near the region of the mutation. The $\mathrm{C}$ to A substitution that results in the introduction of a premature termination codon is indicated by the arrow. 


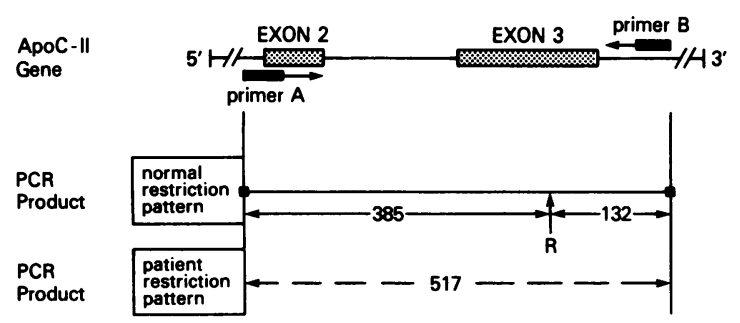

Figure 3. A schematic representation of the portion of the apo C-II gene that was amplified by the PCR is shown. The positions of primers A and B are indicated. The Rsa I site $(R)$ present in the normal amplified DNA is shown. This site is not present in the patient's amplified DNA. The horizontal solid arrows indicate the size of the restriction fragments generated by the digestion of normal amplified DNA by Rsa I. The horizontal dashed arrow illustrates the size of the restriction fragment generated by digestion of the amplified DNA of the patient with Rsa I.

PCR and digestion with Rsa $\mathrm{I}$. The patients' lanes $\left(\mathrm{II}_{1}\right.$ and $\left.\mathrm{II}_{2}\right)$ exhibit only the abnormal 517-bp band. The lanes containing digested DNA of the parents $\left(\mathrm{I}_{1}\right.$ and $\left.\mathrm{I}_{2}\right)$ and offspring $\left(\mathrm{III}_{1}\right.$ and $\mathrm{III}_{2}$ ) have both the normal ( 161 and $416 \mathrm{bp}$ ) and abnormal $(517 \mathrm{bp})$ bands. This finding establishes that the patient is a true homozygote for the $\mathrm{C}$ to A substitution. The offspring's lanes $\left(\mathrm{III}_{1}\right.$ and $\mathrm{III}_{2}$ ) contain lower amounts of amplified DNA, which results in a faint 132-bp band that is clearly visible in the original gel.

Southern blot hybridization of genomic DNA after digestion with Rsa I of a normal subject and the two homozygous members of the Padova kindred is illustrated in Fig. 5. As expected from analysis of the genomic sequence of the normal apo C-II gene (19), digestion of normal DNA with Rsa I leads to the formation of a fragment that was $1,280 \mathrm{bp}$ in length. Digestion of the patient's DNA resulted in a larger, abnormal fragment that was $1,626 \mathrm{bp}$ in length due to the loss of the Rsa I restriction enzyme site caused by the mutation.

Northern blot analysis of total liver RNA from normal subjects and the apo C-II-deficient patient performed by hybridization with an apo C-II cDNA probe is shown in Fig. 6. As expected for a premature termination mutation, the patient's apo C-II mRNA was of normal size when compared with the normal control apo C-II message. Despite the reduced levels of apo C-II present in plasma, the amount of apo C-II
mRNA and protein in the liver of the apo $\mathrm{C}-\mathrm{II}_{\mathrm{Padova}}$ proband was previously shown to be normal by slot blot hybridization and immunohistochemistry (25).

Analyses of apo C-II in the plasma of the normal and apo C-II-deficient subjects were performed by two-dimensional gel electrophoresis and immunoblotting (Fig. 7). As in previous studies (15), normal apo C-II could not be detected in the

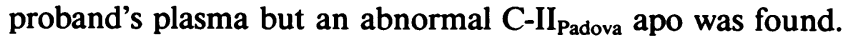
The apparent molecular weight of apo C-II Padova was found to be closer to 8,000 D than to the 4,500 D expected for the 36 amino acid peptide predicted by the sequencing studies. To investigate this discrepancy, a synthetic peptide consisting of the first 36 amino terminal residues of apo C-II was synthesized and analyzed by two-dimensional gel electrophoresis (Fig. 7). Results indicated that the synthetic as well as the native apo C-II peptides comigrated at the same position in the gel and thus have the same $\mathrm{pI}$ and apparent molecular weight, which was larger than that expected for a 36 residue protein. This confirms that the apo C-II Padova protein detected in the patient's plasma by immunoblot studies was the truncated apo C-II protein that exhibited abnormal electrophoretic behavior on two-dimensional gel analysis.

\section{Discussion}

In the present study we analyzed the genetic defect that leads to the deficiency of apo C-II in the proband from the Padova kindred. Sequence analysis of the patient's gene revealed a substitution of a $C$ for an $A$ in exon III that leads to the introduction of a premature termination codon at a position corresponding to amino acid 37 of normal apo C-II and thus to the synthesis of a truncated protein. Since this truncated apo C-II peptide lacks the carboxyl-terminal end that contains the activating domain for apo C-II (26), it will not activate lipoprotein lipase and thus leads to deficiency of apo C-II activity in this patient.

Analysis of the apo C-II gene from immediate family members of the Padova kindred by the PCR, followed by restriction enzyme digestion with Rsa I, established that the two affected individuals were true homozygotes for the mutation. This finding suggested that despite the absence of a family history of consanguinity there is inbreeding in this kindred. The same has been true of other apo C-II-deficient families previously described $(11,12)$.
A

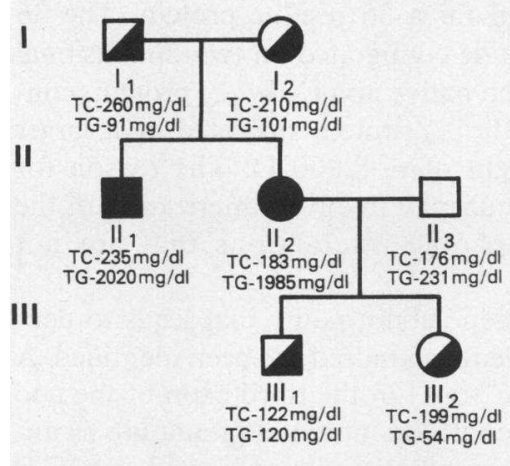

B

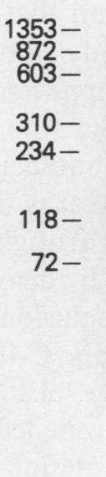

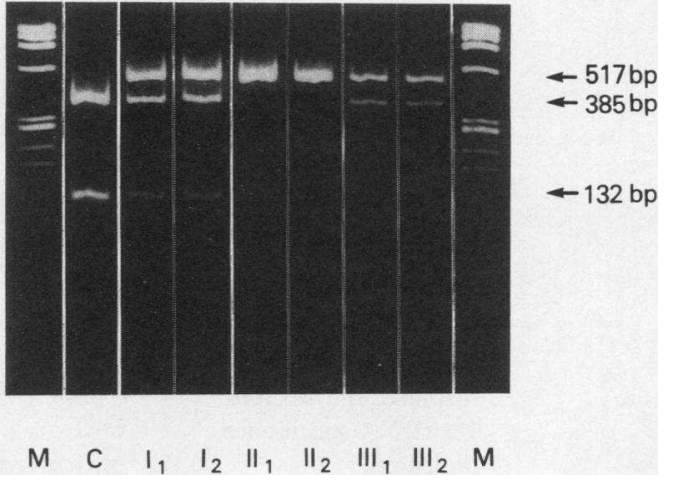

Figure 4. $A$, The family tree of immediate family members of the apo C-II Padova $_{\text {kindred. Total }}$ cholesterol and triglyceride values are shown. $B$, Agarose gel electrophoretic analysis of amplified DNA from the two patients $\left(I I_{I}\right.$ and $\left.I I_{2}\right)$, parents $\left(I_{l}\right.$ and $\left.I_{2}\right)$, and offspring $\left(\mathrm{III}_{1}\right.$ and $\left.\mathrm{III}_{2}\right)$ after digestion with Rsa I. DNA molecular weight markers are shown in the lanes designated $M$. 




Figure 5. Southern blot hybridization of $20 \mu \mathrm{g}$ DNA from the two affected patients $(P T)$ and a normal subject $(N)$ after digestion with Rsa I. The larger, abnormal 1,626-bp fragment is present in both patients.

Northern blot hybridization analysis indicated that the apo C-II mRNA in the patient's liver is of normal size, which is consistent with the premature termination mutation identified by our sequencing analysis. Interestingly, despite markedly reduced plasma apo C-II levels, normal amounts of both apo

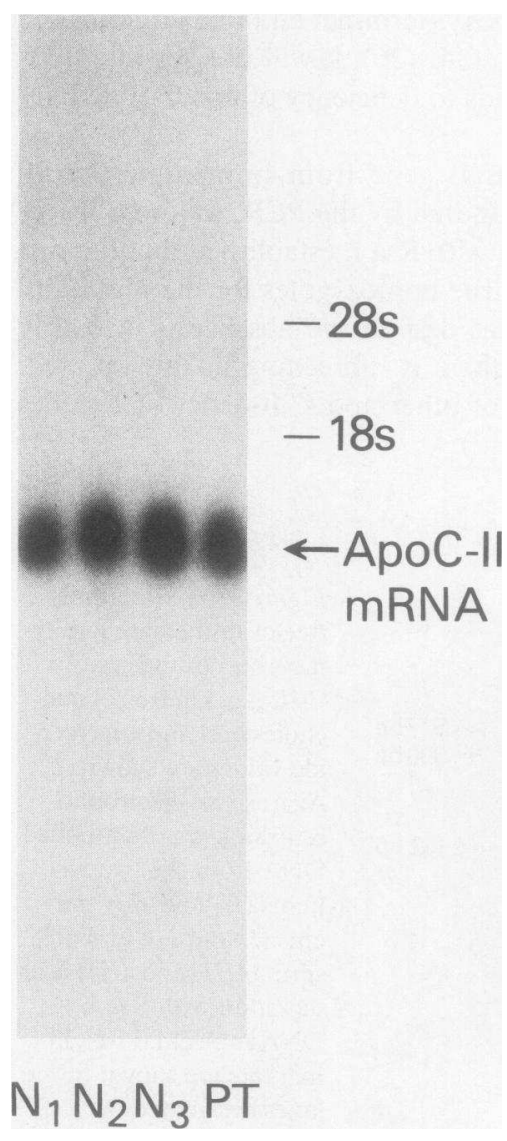

\author{
Figure 6. Northern blo \\ RNA from normal \\ and apo C-II-def- \\ cient $(P T)$ subjects after \\ hybridization with an \\ apo C-II cDNA probe is \\ shown. The relative po- \\ sitions of the $28 \mathrm{~s}$ and \\ 18s rRNA species are \\ indicated.
}
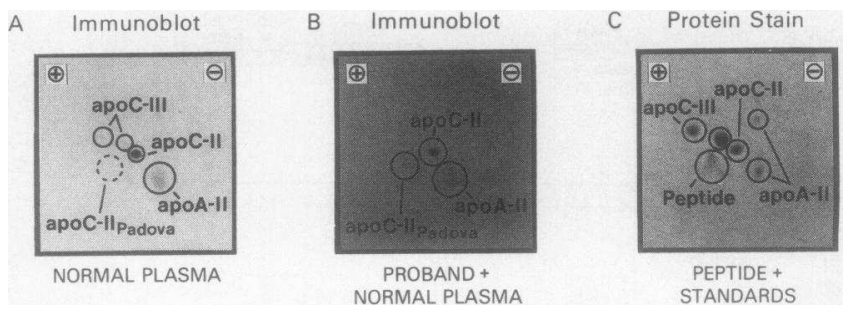

Figure 7. Two-dimensional gel electrophoresis and immunoblot analysis of plasma apo in the region of apo C-II in normal $(A)$ and normal + patient $(B)$ plasma are shown. The electrophoretic position


An apo A-II standard is included as reference. $C$ shows a two-dimensional electrophoretogram stained for protein containing the syn-


standards. The position of the synthetic peptide relative to the apo standards is illustrated. The synthetic peptide exhibits the same pI and aberrant molecular weight as the native apo $\mathrm{C}$ - $\mathrm{II}_{\text {Padova }}$ peptide.

C-II mRNA and protein were detected intrahepatically (26), which suggests that the mutant apo is either abnormally secreted from hepatocytes or rapidly catabolized in plasma. This is in contrast to the apo C-II-deficient proband from Nijmegen (12), who also had a nonsense mutation in exon III (base 2943) and very low intrahepatic levels of apo C-II mRNA. Most in vivo nonsense mutations described to date lead to decreased mRNA accumulation by mechanisms that are not clearly understood. These may involve altered intranuclear stability, abnormal nuclear to cytoplasmic transport of the mRNA, or decreased stability of the intracellular mRNA $(27,28)$. However, two recent studies indicate that a nonsense mutation will not necessarily result in a decreased level of steady-state mRNA $(29,30)$. Thus, normal mRNA levels have been identified for the LDL receptor and the $\beta$-globin chain in patients that have nonsense mutations of these genes. Both of these mutations, as well as the premature termination mutation in

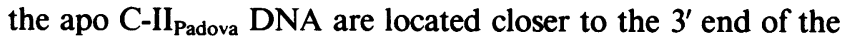
respective genes than other previously described nonsense mutations in those genes. This observation may be similar to what has been described in prokaryotes, where the effect of nonsense mutations on mRNA accumulation is polar, with mutations located near the $5^{\prime}$ end of the gene resulting in lower mRNA accumulation than those closer to the $3^{\prime}$ end (31). It may be that critical nuclear events needed for mRNA accumulation do not occur with more proximal mutations.

Analysis of plasma from the apo C-II-deficient patient by two-dimensional electrophoresis and immunoblotting revealed a protein that exhibited a larger apparent molecular weight than that expected for a 36 residue protein. The 36 amino acid synthetic peptide comigrated on two-dimensional gel electrophoresis with the native apo $\mathrm{C}_{-}$II $_{\text {Padova }}$ protein, con-

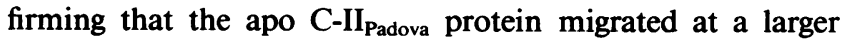
apparent molecular weight of $\sim 8,000 \mathrm{D}$. The reason for this behavior is unclear, but may involve dimerization of the peptide through hydrophobic interactions that are not disrupted by detergents.

In conclusion, the genetic abnormality that leads to deficiency of apo C-II in the Padova kindred has been identified. A single base substitution (C to $A$ ) in the third exon of the apo

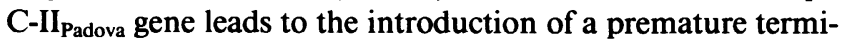
nation mutation and the synthesis of a truncated apo C-II 
protein that can be identified in plasma by immunoblotting. Since the carboxyl-terminal half of apo C-II is missing in apo C-II $\mathrm{I}_{\text {Padova }}$, the protein does not activate lipoprotein lipase and thus results in the development of type I hyperlipoproteinemia in this kindred.

\section{References}

1. Hospattankar, A. V., T. Fairwell, R. Ronan, and H. B. Brewer, Jr. 1984. Amino acid sequence of human plasma apolipoprotein C-II from normal and hyperlipoproteinemic subjects. J. Biol. Chem. 259:318-322.

2. Breckenridge, W. C., J. A. Little, G. Steiner, A. Chow, and M. Poapst. 1978. Hypertriglyceridemia associated with deficiency of apolipoprotein C-II. N. Engl. J. Med. 298:1265-1273.

3. Yamamura, T., H. Sudo, K. Ishikawa, and A. Yamamoto. 1979. Familial type I hyperlipoproteinemia caused by apolipoprotein C-II deficiency. Atherosclerosis. 34:53-65.

4. Miller, N. E., S. N. Rao, P. Alaupovic, N. Noble, J. Slack, J. D. Brunzell, and B. Lewis. 1981. Familial apolipoprotein C-II deficiency: plasma lipoproteins and apolipoproteins in heterozygous and homozygous subjects and the effects of plasma infusion. Eur. J. Clin. Invest. 11:69-76.

5. Stalenhoef, A. F. H., A. F. Casparie, P. N. M. Demacker, J. T. J. Stouten, J. A. Lutterman, and A. van't Laar. 1981. Combined deficiency of apolipoprotein C-II and lipoprotein lipase in familial hyperchylomicronemia. Metab. Clin. Exp. 30:919-926.

6. Catapano, A. I., G. L. Mills, P. Roma, M. LaRosa, and A. Capurso. 1983. Plasma lipids, lipoproteins and apoproteins in a case of apoC-II deficiency. Clin. Chim. Acta. 130:317-327.

7. Saku, K., C. Cedres, B. McDonald, B. A. Hynd, B. W. Liu, L. S. Srivastava, and M. L. Kashyap. 1984. C-II anapolipoproteinemia and severe hypertriglyceridemia. Am. J. Med. 77:457-462.

8. Baggio, G., E. Manzato, C. Gabelli, R. Fellin, S. Martini, G. Baldo Enzi, F. Verlato, M. R. Baiocchi, D. L. Sprecher, M. L. Kashyap, H. B. Brewer, Jr., and G. Crepaldi. 1986. Apolipoprotein C-II deficiency syndrome. Clinical features, lipoprotein characterization, lipase activity, and correction of hypertriglyceridemia after apolipoprotein C-II administration in two affected patients. J. Clin. Invest. 77:520-527.

9. Brunzell, J. D., N. E. Miller, P. Alaupovic, R. J. St. Hilaire, C. S. Wang, D. L. Sarson, S. R. Bloom, and B. Lewis. 1988. Familial chylomicronemia due to a circulating inhibitor of lipoprotein lipase. J. Lipid Res. 24:12-19.

10. Kihara, S., Y. Matsuzawa, M. Kubo, S. Nozaki, T. Funahashi, S. Yamashita, N. Sho, and S. Tarui. 1989. Autoimmune hyperchylomicronemia. N. Engl. J. Med. 320:1255-1259.

11. Fojo, S. S., U. Beisiegel, U. Beil, K. Higuchi, M. Bojanovski, R. E. Gregg, H. Greten, and H. B. Brewer, Jr. 1988. Donor splice site mutation in the apolipoprotein (apo) C-II gene (apoC- $\mathrm{II}_{\mathrm{Hamburg}}$ ) of a patient with apoC-II deficiency. J. Clin. Invest. 82:1489-1494.

12. Fojo, S. S., A. F. H. Stalenhoef, K. Marr, R. E. Gregg, and H. B. Brewer, Jr. 1988. A deletion mutation in the apoC-II gene (apoC$\mathrm{II}_{\text {Nijmegen }}$ ) of a patient with a deficiency of apolipoprotein C-II. J. Biol. Chem. 263:17913-17916.

13. Connelly, P. W., G. F. Maguire, T. Hofmann, and J. A. Little. 1987. Structure of apolipoprotein C-II Toronto $_{\text {, a nonfunctional human }}$ apolipoprotein. Proc. Natl. Acad. Sci. USA. 84:270-273.

14. Connelly, P. W., G. F. Maguire, and A. J. Little. 1987. Apolipoprotein $\mathrm{C}_{\text {-II }}$ St. Michael. Familial apolipoprotein C-II deficiency associated with premature vascular disease. J. Clin. Invest. 80:1597-1606.

15. Baggio, G., E. Manzato, C. Gabelli, R. Fellin, S. Martini,
G. Baldo Enzi, F. Verlato, M. R. Baiocchi, D. L. Sprecher, M. L. Kashyap, H. B. Brewer, Jr., and G. Crepaldi. 1986. Apolipoprotein C-II deficiency syndrome. Clinical features, lipoprotein characterization, lipase activity and correction of hypertriglyceridemia after apolipoprotein C-II administration in two affected patients. J. Clin. Invest. 77:520-527.

16. Chirgwin, J. A., A. E. Przybyla, R. J. MacDonald, and W. J. Rutter. 1979. Isolation of biologically active ribonucleic acid from sources enriched in ribonuclease. Biochemistry. 18:5294-5299.

17. Fojo, S. S., S. L. Law, D. L. Sprecher, G. Baggio, and H. B. Brewer, Jr. 1984. Analysis of the apoC-II gene in apoC-II deficient patients. Biochem. Biophys. Res. Commun. 124:308-313.

18. Wong, C., C. E. Dowling, R. K. Saiki, R. G. Higuchi, H. A. Erlich, and H. H. Kazazian. 1987. Characterization of $\beta$-thalassaemia mutations using direct genomic sequencing of amplified single copy DNA. Nature (Lond.). 330:384-386.

19. Fojo, S. S., S. L. Law, and H. B. Brewer, Jr. 1987. The human preproapolipoprotein C-II gene: complete nucleic acid sequence and genomic organization. FEBS (Fed. Eur. Biochem. Soc.) Lett. 213:221-226.

20. Sanger, F., A. R. Coulson, B. G. Barell, A. J. H. Smith, and B. A. Roe. 1980. Cloning in single-stranded bacteriophage as an aid to rapid DNA sequencing. J. Mol. Biol. 143:161-178.

21. Meinkoth, J., and G. Wahl. 1984. Hybridization of nuclear acids immobilized on solid supports. Anal. Biochem. 138:267-284.

22. Fairwell, T., A. V. Hospattankar, H. B. Brewer, Jr., and S. A. Khan. 1987. Human plasma apolipoprotein C-II: total solid-phase synthesis and chemical and biological characterization. Proc. Natl. Acad. Sci. USA. 84:4796-4800.

23. Sprecher, D. L., L. Taam, and H. B. Brewer, Jr. 1984. Two dimensional electrophoresis of human plasma apolipoproteins. Clin. Chem. 30:2984-2992.

24. Merrill, C. R., D. Goldman, S. A. Sedman, and M. H. Ebert. 1981. Ultrasensitive stain for proteins in polyacrylamide gels show regional variation in cerebrospinal fluid proteins. Science (Wash. DC). 211:1437-1438.

25. Fojo, S. S., G. Baggio, C. Gabelli, K. Higuchi, M. Bojanovski, R. E. Gregg, and H. B. Brewer, Jr. 1988. Apolipoprotein C-II deficiency: identification of a structural variant apoC-II $\mathrm{Iadova}_{\text {. Biochem. }}$ Biophys. Res. Commun. 154:73-75.

26. Kinnunen, P. K. J., R. L. Jackson, L. C. Smith, A. M. Gotto, Jr., and J. T. Sparrow. 1977. Activation of lipoprotein lipase by native and synthetic fragments of human plasma apolipoprotein C-II. Proc. Natl. Acad. Sci. USA. 74:4848-4851.

27. Baserga, S. J., and E. J. Benz, Jr. 1988. Nonsense mutations in the human $\beta$-globin gene affect mRNA metabolism. Proc. Natl. Acad. Sci. USA. 85:2056-2060.

28. Humphries, K. R., T. J. Ley, N. P. Anagnou, A. W. Baur, and A. W. Nienhuis. 1984. $\beta-39$ thalassemia gene. A premature codon causes $\beta$-mRNA deficiency mutant without affecting cytoplasmic $\beta$ mRNA stability. Blood. 64:23-32.

29. Lerhman, M. A., W. J. Schneider, M. S. Brown, C. G. Davis, A. Elhammer, D. W. Russell, and J. L. Goldstein. 1987. The Lebanese allele at the low density lipoprotein reception locus: nonsense mutation produces truncated receptor that is retained in endoplasmic reticulum. J. Biol. Chem. 262:401-410.

30. Liebhaber, S. A., M. B. Coleman, J. G. Adams III, F. E. Cash, and M. H. Steinberg. 1987. Molecular basis for nondeletion $\alpha$-thalassemia in American black $\alpha 2^{116 \mathrm{GAG} \rightarrow \mathrm{UAG}} . J$. Clin. Invest. 80:154-159.

31. Adhya, S., and M. Gottesman. 1978. Control of transcription termination. Annu. Rev. Biochem. 47:967-996. 